\title{
Author's Reply: Early Consequences of Pectus Excavatum Surgery on Self-Esteem and General Quality of Life
}

\author{
Wietse P. Zuidema ${ }^{1}$
}

Published online: 28 August 2018

(c) Société Internationale de Chirurgie 2018

We thank Darling $\mathrm{C}$ et al. for their interest in our article "Early consequences of pectus excavatum surgery on selfesteem and general quality of life", recently published in the World Journal of Surgery [1].

Pain management in patients undergoing surgical correction of a pectus excavatum remains challenging.

The authors describe an interesting alternative technique for peri-operative pain management during Nuss bar placement in a patient with a pectus excavatum.

Although pain management with an epidural catheter is widely used after surgical pectus excavatum correction, it has downsides. One of the drawbacks of the use of the epidural in adolescents is that it is placed when the patients are already under general anaesthesia and testing of correct functioning is no longer possible. Consequently, some patients experience severe pain after surgery. Regional blocks may be an interesting alternative [2].

We agree that the erector spinae block (ESPB) may be helpful in pain management of pectus excavatum patients receiving a Nuss bar placement. However, to evaluate the use of ESPB in this patients group, a larger number of patients need to be assessed concerning effect on VAS score and QoL.

Since it is mainly the anaesthetist performing this technique, training this new technique in that professional discipline is also an issue which needs attention.

On behalf of all authors

Wietse P. Zuidema

Compliance with ethical standards

Conflict of interest The authors declare that they have no conflict of interest.

\section{References}

1. Zuidema WP, Oosterhuis JWA, Zijp GW et al (2018) Early consequences of pectus excavatum surgery on self-esteem and general quality of life. World J Surg. https://doi.org/10.1007/ s00268-018-4526-9

2. Loftus PD et al (2016) Paravertebral regional blocks decrease length of stay following surgery for pectus excavatum in children. J Pediatr Surg 51(1):149-153
Wietse P. Zuidema

w.zuidema@vumc.nl

1 Amsterdam, The Netherlands 